\title{
Eğirme Türünün Haşıl Sonrası İplik Özelliklerine Etkisi
}

\author{
Pinar DURU BAYKAL ${ }^{* 1}$, Zehra KUMAŞ ${ }^{1}$ \\ ${ }^{1}$ Çukurova Üniversitesi, Mühendislik Fakültesi, Tekstil Mühendisliği Bölümü, Adana
}

Geliş tarihi: 19.03.2021 Kabul tarihi: 30.06.2021

\section{Öz}

Kaliteli ve verimli bir dokuma işlemi için çözgü iplikleri haşıllanmalıdır. Farklı iplik türleri arasındaki yapısal farklılıkların bilinmesi, haşıl reçetesinin belirlenmesi ve yeterli haşıl alımının sağlanması için büyük önem taşımaktadır. Bu çalışmada, eğirme türünün haşıllanmış iplik kalitesine etkisinin araştırılması amacıyla \%100 pamuk ring ve rotor iplikleri aynı reçete ile haşıllanmıştır. İpliklerin haşıl öncesi ve sonrası mukavemet-uzama, aşınma, düzgünsüzlük, iplik hataları ve tüylülük özellikleri karşılaştırılmıştır. Haşıllama işleminin farklı iplik yapılarında kaliteye farklı derecede etkileri gözlenmiştir.

Anahtar Kelimeler: Haşıllama, Ring ipliği, Rotor ipliği, İplik kalitesi, İplik yapısı

\section{Effect of Spinning Type on Yarn Properties After Sizing}

\begin{abstract}
For a quality and efficient weaving process, warp threads should be sized. Knowing the structural differences between different yarn types is important for determining the sizing recipe and ensuring adequate sizing. In this study, $100 \%$ cotton ring and rotor yarns were sized with the same recipe in order to investigate the effect of spinning type on sized yarn quality. Strength, elongation, abrasion, unevenness, defects and hairiness properties of yarns were compared before and after sizing. It has been observed that the sizing process has different effects on the quality of different yarn structures.
\end{abstract}

Keywords: Sizing, Ring yarn, Rotor yarn, Yarn quality, Yarn structure

*Sorumlu yazar (Corresponding author): Pınar DURU BAYKAL, pduru@cu.edu.tr 


\section{GíRiş}

Çözgü ipliği, dokuma sırasında gerilme, aşınma ve eğilme nedeniyle karmaşık mekanik kuvvetlere maruz kalır. Haşıllamanın birincil amac1 ve nedeni, dokumadaki darbeli ve gerilimli çalışmaya dayanabilecek şekilde çözgülere dokunabilirlik sağlamak, böylece çözgü iplik kopuşlarını azaltarak kaliteyi ve verimliliği yükseltmektir.

Elyaf türü, iplik türü, haşıl kimyasalları, dokuma sonrası kolay sökülebilirliği ve çevre kirliliği parametreleri ile etkileşim halinde olan haşıllama işlemi oldukça karmaşıktır.

İplik kesitindeki haşıl dağılımının farklı olasılıkları Şekil 1'de gösterilmiştir [1]. Şekil 1d'de haşılın ipliğe nüfuz etmesi ve ipliğin etrafında koruyucu bir tabaka sağlanması arasında optimal bir dengenin olduğu durum gösterilmiştir. İpliğin çevresindeki fazla haşıl, uygulanan kuvvetler altında tezgahta dökülme eğiliminde olacaktır. Şekil 1a'da gösterildiği gibi, çok fazla penetrasyon, aşındırma etkisine karşı korumak için iplik yüzeyinde çok az miktarda haşıl bırakabilir. Böyle bir durumda, gerekli koruyucu yüzey kaplamasını sağlamak için daha fazla haşıl eklentisi gerekir.

İpliğin mukavemet özelliği, dokuma sırasında çözgü ipliğinin performansını etkileyen ana faktör olarak kabul edilmiștir. Ancak son yıllarda uzama, tüylülük, aşınma direnci ve nem emilimi gibi özelliklerin dokuma tezgahındaki performans üzerinde eşit derecede etkili olduğu anlaşılmıştır [2].

İpliğin fiziksel ve mekanik özellikleri, sadece ipliğin yapıldığı liflerin özelliklerine değil, aynı zamanda bunların iplik içindeki dizilişine, yani iplik yapısına da bağlıdır. Farklı iplik türleri arasındaki yapısal farklılıkların bilinmesi, haşıl reçetesinin belirlenmesi ve yeterli haş1 alımının sağlanması için büyük önem taşımaktadır [2].

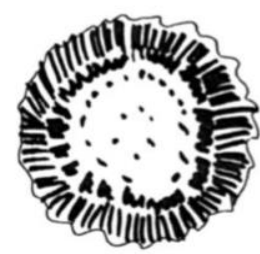

(a)

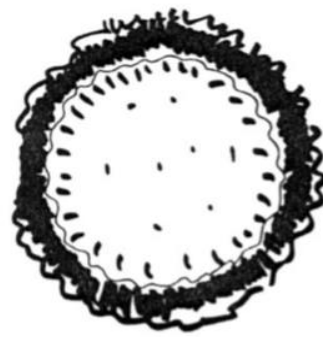

(c)

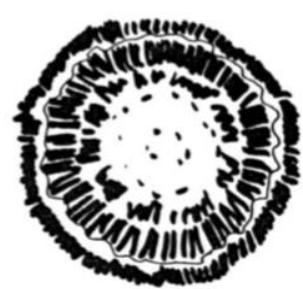

(b)

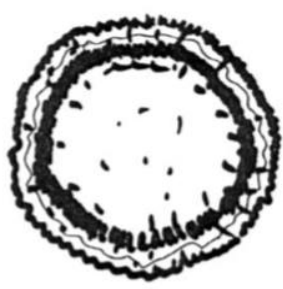

(d) (a) çok fazla penetrasyon, yüzey kaplaması yok

(b) çok fazla penetrasyon, yüzey kaplaması sağlamak için daha fazla haşıl eklendi

(c) çok az penetrasyon, iplik yapısına bağlanma yok (d) optimal dağılım

Şekil 1. Haşıl dağılımının şematik gösterimi

Ring eğirme sırasında iplikteki lifler paraleldir ve birlikte dönerek bükülürler, böylece maksimum lif yoğunluğu özde en yüksektir ve iplik çevresine doğru azalır. Lifler ipliğin iç kısmından dıș kısmına göç ederek iplik içinde çok güçlü kohezyon oluşturur (Şekil 2a). Ring ipliğin bu kohezyon yapısı güçlüdür, ancak daha düşük bir emme kapasitesine sahip olup, haşıllama sonrasında iplikte az miktarda haşıl almaya neden olur [2].

Open-End (OE) rotor ipliği, oldukça düzensiz bir büküm yapısına sahiptir. Bazı lifler paralel büküm almayıp iplik uzunluğu boyunca farklı büküm açısı ile gelişi güzel sarma bağı oluşturarak eğrilirler. Böylece rotor ipliği, merkezde paralel olarak düzenlenmiş lifler ile paralel liflerin etrafını saran liflerden oluşur. İplik eğirme işlemi sırasında meydana gelen sarg1 liflerinin sayısı oldukça fazladır ve bunlar iplikteki gerçek lif aralığını azaltır, yani lif göçü azalır. Bu durum zayıf ancak hacimli bir yapıya neden olur (Şekil 2b). Ancak iyi emici özellikleri, iplikte daha fazla miktarda haşıl alımına neden olur [2]. 
Rotor ipliklerinde düşük mukavemet varyasyonu genellikle sonraki işlem kademelerinde stabil çalışma sağlar. Hacimli ve emici iplik yapısı nedeniyle rotor iplik haşıl maddesini hızla absorblar ve dokuma sektöründe iyi çalışma özellikleri için ringe göre daha az haşıl maddesi ile çalışmaya olanak sağlar [3].

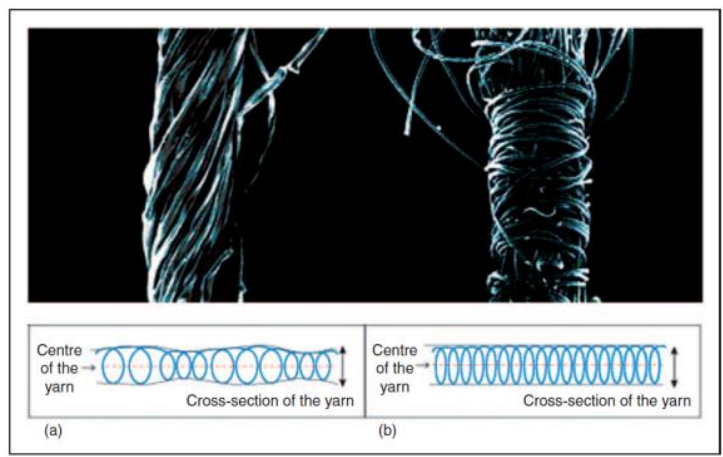

Şekil 2. Ring (a) ve Rotor (b) iplik yapısı

Ring ve rotor iplikleri içerisinde lif yerleşimleri ve iplik yapıları Şekil 3 ve 4'te verilmiştir [4]. Ring ipliği üretiminde bükümün yönü dışarıdan (dış tabakadan) içeri (merkeze, çekirdeğe) doğrudur. Rotor ipliği üretiminde ise iplik bükümü içeriden (çekirdekten) diş tabakaya doğru gerçekleşir, eğirme süresince liflerin bükümden kurtulamadığ iç kısımlarda yapı çok fazla kompakt ve sıkı hale gelmekte ve sonuçta çok sıkı bir içyapı ortaya çıkmaktadır. Şekil 3, rotor ipliğinin merkezinin dışından daha sıkı paketlendiğini, oysaki ring ipliğin bu açıdan nispeten üniform olduğunu göstermektedir.

Ring eğirmede tabaka şeklinde bükülmüş bir iplik yüksek gerilme dayanımına (mukavemetine) sahip olmasına rağmen, aşınmaya karşı fazla dayanıklı değildir. İpliğin aşınmaya karşı zorlanması durumunda, öncelikle kuvvetlice gerilmiş diş tabakadaki lifler zarar görmekte ve ipliği oluşturan lifleri bir arada tutan liflerin zarar görmesiyle de içerideki lifler kohezyonu kaybetmektedir.

Rotor eğirmede çekirdek büküm olarak isimlendirilen yapının tipik özelliği hacimli bir tutum ile birlikte düşük bir dayanımdır. Dış kısımda liflerin düşük bükümlü olmaları nedeniyle, iplik dayanımına fazla bir katkıları yoktur. Buna karşın bu tür ipliklerin aşınma dayanımları iyidir. Aşınma etkisinde dış tabakadaki liflerin uzaklaştırılmış ya da zarar görmüş olması çok fazla önemli değildir. Çünkü bu liflerin zaten çok fazla iplik mukavemetine katk1sı yoktur [4,5].

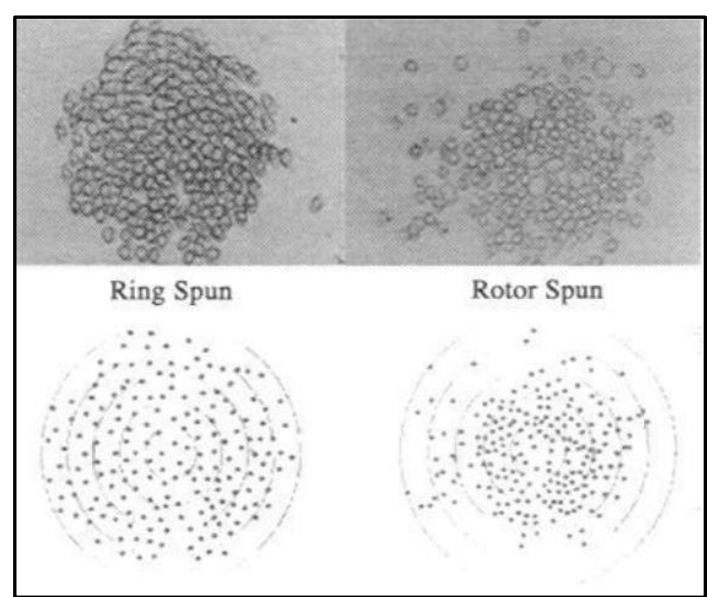

Şekil 3. İplik içerisinde lif yerleşimi

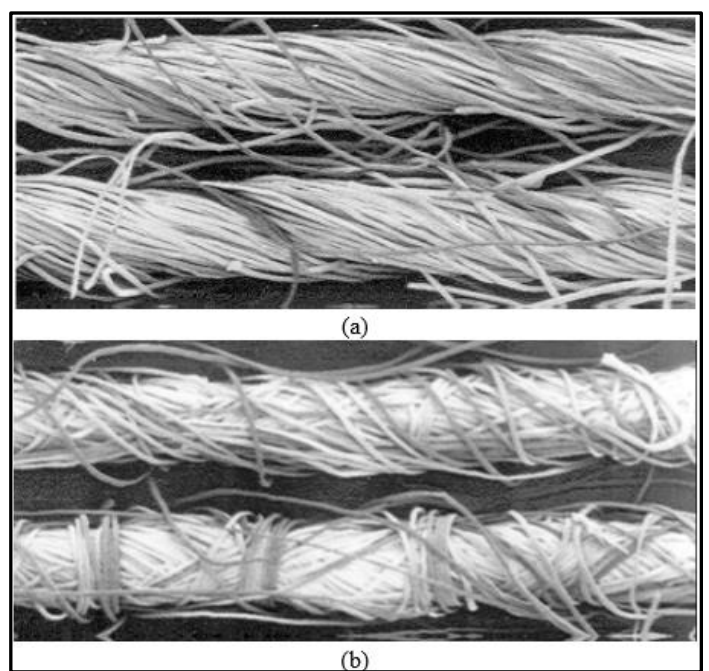

Şekil 4. Ring (a) ve rotor (b) İplik yapıları

Literatürde haşıllama ile ilgili pek çok çalışma olmasına karşın iplik türünün haşıllama üzerindeki etkilerinin incelendiği ve farklı iplik yapılarının haşıllı özelliklerinin karşılaştırıldığı çok az çalışmaya rastlanmıştır. 
Thomas ve Zeiba (2000), çalışmalarında hava jetli ve ring çözgü iplikleri için haşıl yağlama yöntemini araştırmışlardır. Ring ve hava jetli pamuk-polyester karışımı iplikler modifiye mısır nişastası, polivinil alkol ve ek olarak yağlayıcı vaks kullanılarak haşıllanmıştır. İplikler mukavemet, uzama ve aşınma direnci açısından test edilmiştir ve performans farklılıkları istatistiksel olarak karşılaştırılmıştır. Haşıl teknesinde yağlayıcı ve vaks kullanımı haşıllı ring ipliklerdekine benzer bir şekilde haşıllı hava jetli ipliklerin kopma mukavemetini, uzamasını ve aşınma direncini azaltmıştır [6].

Sengupta ve arkadaşları (2002a), çalışmalarında ring ve rotor pamuk ipliklerini farklı konsantrasyonlarda nişasta ve PVA haşıl maddeleri ile haşıllamışlardır. Hem haşıllı hem de haşıllanmamış ring ve rotor ipliklerine aşınma ve mukavemet testleri yapılmıştır. Ayrıca aşınma testi sonrasında ipliklerin mukavemet kayıpları da test edilerek değerlendirilmiştir. 125 aşındırma darbesinden sonra nişasta ile haşıllı ipliklere göre PVA ile haşıllı ipliklerin mukavemet kaybı çok daha az olmuştur. Farklı konsantrasyonlarda kullanılan haşıl maddeleri ring ve rotor ipliklerinin mukavemetinde farklı değişiklikler meydana getirmiştir [7].

Sengupta ve arkadaşları (2002b), tarafından yapılan çalışmada ring ve rotor pamuk ipliklerine farklı konsantrasyonlarda PVA haşıl maddesi ile farklı sıcaklıklarda haşıllama işlemi uygulanmıştır. Hem haşıllı hem de haşıllanmamış ring ve rotor ipliklerine aşınma ve mukavemet testleri yapılmıștır. Haşıl konsantrasyonun artması hem ring hem de rotor ipliklerinde daha iyi aşınma direnci sağlamıştır. Sonuçlar haşıllı ipliklerdeki aşınma direncinin, rotor iplikler için, düşük viskoziteli haşıllanmıș ve yüksek sıcaklıkta kurutulanlar için ring ipliklerden daha yüksek olduğunu göstermiştir [8].

Sengupta ve arkadaşları (2002c), tarafından yapılan çalışmada hava jetli, ring ve rotor polyester/viskon (70:30) iplikler PVA haşıl maddesi ile farklı sıcaklıklarda haşıllanmıştır. Hem haşıllı hem de haşıllanmamış ipliklere aşınma ve mukavemet testleri yapılmıştır. Haşıllama işleminden sonra ring, rotor ve hava jetli ipliklerin mukavemetinde artış gözlenirken kopma uzamaları ise azalmıştır. Yüzde değişime bakıldığında mukavemet artışı en çok rotor ipliklerde, en az ise ring ipliklerde gözlenmiştir. Rotor ve hava jetli ipliklerin uzama değerleri hemen hemen birbirine yakın çıkmıştır. Ring ipliklerin uzamasındaki değişim rotor ve hava jetli ipliklere göre düşük bulunmuştur [9].

Behera ve Joshi (2006), çalışmalarında Dref ipliklerin dokunabilirliğine haşıllamanın etkisini araştırmışlardır. Çalışmada core-spun Dref ipliği ve \%100 Dref pamuk ipliği kullanılmıştır. Haşıllama işlemi laboratuvar haşıl makinesinde modifiye nişasta ve akrilik haşıl maddeleri ile yapılmıştır. Tüm ipliklerin dokuma performansı, dokuma gerilimlerini simüle eden Reutilingen Web Tester cihazında değerlendirilmiştir. Dref ipliklerinin dokuma performansını arttıran optimum haşıl oranı yaklaşık \%15 olarak bulunmuştur [10].

Schwarz ve arkadaşları (2010), çalışmalarında haşıllanan ipliğin mekanik ve deformasyon özelliklerini analiz etmişlerdir. Aynı reçete ve iki farklı haşıl konsantrasyonu kullanılarak haşıllanan ring ve rotor iplikleri haşıllama öncesi ve sonrası analiz edilmiştir. Haşıllama ile ring ipliklerinde önemli iyileştirmeler elde edilmiştir. Rotor ipliklerinde ise iplik yapısı nedeniyle iyileşmeler düşüktür. Haşıllama işlemi ile özellikle ring ve rotor ipliklerinin haşıllama öncesi tüylülüğündeki farklılık hemen hemen eşitlenmiştir. Ring ve rotor ipliklerinin haşıl alma oranları karşılaştırıldığında, ring ipliklerinin kompakt yapıları nedeniyle haşıl alma oranının rotor ipliklere göre daha düşük olduğu görülmüştür [2].

Ring ve rotor iplik yapıları birbirinden oldukça farklıdır. $\mathrm{Bu}$ yapısal farklılığın haşıl işleminden nasıl etkileneceğini belirlemek üzere, özellikleri birbirine oldukça yakın hammaddeler ile yaklaşık aynı numarada ring ve rotor iplikleri üretilmiş ve bu ipliklere bobin haşıl makinesinde aynı reçete ile haşıllama yapılmıştır. Haşılsız ve haşıllı ipliklere mukavemet-uzama, aşınma, düzgünsüzlük, hata ve tüylülük testleri yapılarak sonuçlar iplik kalite parametreleri açısından değerlendirilmiştir. 


\section{MATERYAL VE METOD}

\subsection{Materyal}

Çalışmada ring eğirme sistemi için Urfa pamuğu (rollergin) kullanılırken rotor eğirme sistemi için Amerikan pamuğu (sawgin) kullanılmıştır. Hem Urfa hem de Amerikan pamuğunda 12'şer balyada
HVI ölçümleri yapılmış olup ortalama değerler Çizelge 1'de verilmiştir.

Çizelgede görüldüğü gibi ring ve rotor iplik üretiminde kullanılan pamuk elyafının incelik, uzunluk, üniformite, mukavemet-uzama değerleri birbirine oldukça yakındır.

Çizelge 1. Elyaf özellikleri

\begin{tabular}{|l|c|c|c|c|c|c|c|c|}
\hline Pamuk & SCI & $\begin{array}{c}\text { İcelik } \\
(\mathbf{M i c})\end{array}$ & $\begin{array}{c}\text { UHML } \\
(\mathbf{m m})\end{array}$ & $\begin{array}{c}\text { Olgunluk } \\
(\mathbf{M a t})\end{array}$ & $\begin{array}{c}\text { UI } \\
(\boldsymbol{\%})\end{array}$ & $\begin{array}{c}\text { SFI } \\
(\boldsymbol{\%})\end{array}$ & $\begin{array}{c}\text { Mukavemet } \\
(\mathbf{g} / \text { tex })\end{array}$ & $\begin{array}{c}\text { Uzama } \\
(\boldsymbol{\%})\end{array}$ \\
\hline Urfa (rollergin) & 140 & 4,45 & 29,67 & 0,90 & 83,23 & 7,42 & 32,63 & 6,96 \\
\hline Amerikan (sawgin) & 146 & 4,48 & 30,24 & 0,90 & 83,28 & 7,80 & 33,70 & 6,92 \\
\hline
\end{tabular}

\subsection{Metod}

\subsection{1. İplik Üretimi}

İplik üretimi Şekil 5'te verilen iş akışına göre gerçekleştirilmiştir. Ne 6,40 inceliğinde ring ipliği ve $\mathrm{Ne} 6,32$ inceliğinde rotor ipliği üretilmiştir. Ring ipliği üretiminde iğ devri $7.000 \mathrm{~d} / \mathrm{dk}$, büküm $427,95 \mathrm{tur} / \mathrm{m}$; rotor ipliği üretiminde ise rotor devri 80.000 d/dk, büküm 445,28 tur/m'dir.

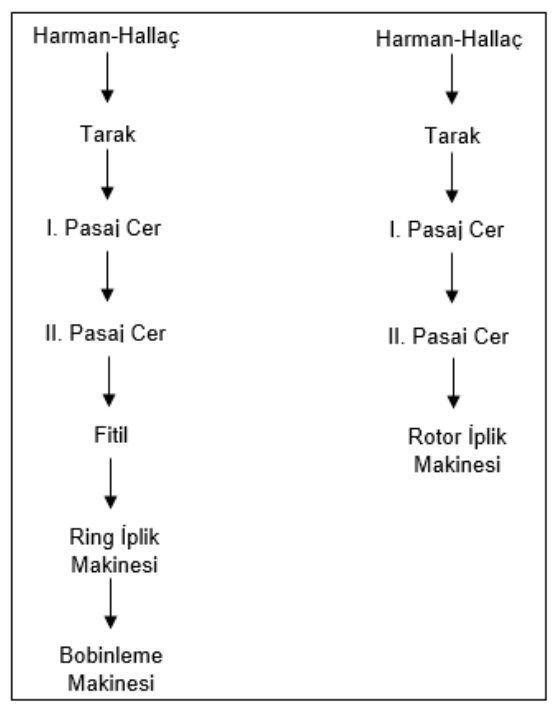

Şekil 5. İplik üretim süreci

\subsubsection{Haşıllama İşlemi}

Çalışmada haşıl maddesi olarak Dystar firmasının polivinil alkol (PVA) esaslı haşıl maddesi (Lava
Fin 936 conc) kullanılmıştır. İpliklerin haşıl alma oran 1 ise $\% 8$ dir. Hem ring iplikleri hem de rotor iplikleri aynı reçete ile bobinden-bobine haşıl makinesinde haşıllanmıştır.

Bilgisayar kontrollü, elektrikli haşıl pişiricisi ve kurutma kabini ile donatılmış olan bobindenbobine haşıllama (tek bobin haşıl) makinesi, Şekil 6'da verilmiştir. Haşıl, haşıl pişiricisi ve haşıl teknesi arasında elektrikli pompa ile devir daim ettirilir, sıkma silindirleri ile haşıl alma oranı kontrol edilir.

Kurutma bölgesi elektrik kontrollüdür ve elektrikli 1sitma ile sicak hava uygulayarak kurutma yapilır. Klasik haşıllama işleminden farklı olarak burada tek bir bobin kullanılır ve haşıllamadan sonra tek bir bobine haşıllı iplikler sarılır.

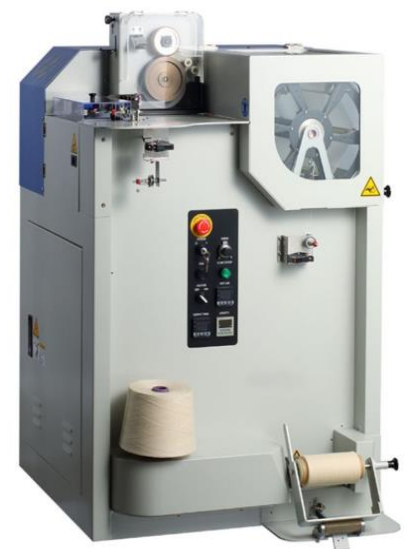

Şekil 6. Bobinden-Bobine Haşıl Makinesi 


\subsection{3. İpliklere Uygulanan Testler}

Ring ve rotor ipliklerine haşıl öncesi ve haşıl sonrası kopma mukavemeti ve kopma uzamas1, aşınma dayanımı, düzgünsüzlük, iplik hataları ve tüylülük testleri yapılmıştır.

\subsubsection{1. İplik Kopma Mukavemeti ve Kopma Uzaması Testi}

İplik kopma mukavemeti ve kopma uzaması testi Uster Tensojet 4 cihazı ile 'TS EN ISO 2062 Tekstil-Paketlerden alınan iplikler- Tek ipliğin kopma kuvvetinin ve kopma anındaki uzamasının sabit hızlı uzama cihazı (CRE- Constant Rate of Extension) kullanılarak tayini' standardı esas alınarak yapılmıştır. Cihazın test hızı $400 \mathrm{~m} / \mathrm{dk}$, test uzunluğu 500 mm'dir. Her bobinde 100 ölçüm yapılmıştır.

\subsubsection{2. İplik Düzgünsüzlüğü, İplik Hataları ve Tüylülük Testi}

Uster Tester 4-S cihazı ile ipliklerin düzgünsüzlük, ince yer, kalın yer ve neps değerleri ile tüylülüğü test edilmiştir. Test $400 \mathrm{~m} / \mathrm{dk}$ hızda gerçekleştirilmiştir. Her bobinde 5 ölçüm yapılmıştır.

\subsubsection{3. İplik Așınma Dayanımı Testi}

İpliklerin aşınma dayanımının tespiti için belirlenen herhangi bir standart bulunmamaktadır. Çalışma kapsamında Zweigle G 551 aşınma test cihazı kullanılmıştır. Test için iplik numarasına göre ağırlık takılarak belirli uzunlukta 20 adet iplik cihaza bağlanır. Aşınma dayanımı testi, her 20 adet ipliğin aşınma işlemine tabi tutulması sonucu kopması ile gerçekleşmektedir. İplikler makinenin çalışmasıyla ileri-geri hareket eden zımpara kağıdı ile kaplanmış silindirin dönme hareketi ile üzerindeki zımparaya sürtme sonucu aşınarak kopmaya başlarlar. Her kopuş olduğunda makine durdurulur. Koptuğu andaki sayaç değeri not edilir. $\mathrm{Bu}$ işlem 20 tane iplik kopuncaya kadar devam eder. 20 değerin ortalaması alınarak aşınma değeri bulunur.

\section{BULGULAR VE TARTIŞMA}

Haşılsız ve haşı1lı ring ve rotor ipliklerinin ölçülen kalite parametreleri Çizelge 2'de verilmiştir. İplik özelliklerinde meydana gelen değişim \% olarak ifade edilmiştir.

\section{1. İplik Kopma Mukavemeti ve Uzaması}

Ring iplik eğirme sisteminde iplik yapısı yüksek oranda eksene ve birbirine paralel liflerden oluşmaktadır. Liflerin paralel yerleşimi ve bükümü, ring iplik mukavemetinin rotor ipliklere göre daha yüksek olmasına neden olmaktadır. Bu durum gerek haşıl öncesi ve gerekse de haşıl sonrası gözlenmiştir (Çizelge 2 ve Şekil 7). Ancak haşıllama sonrasında ring ipliklerinin mukavemet artış1 \%15,75 iken rotor ipliklerinde bu artış $\% 17,95$ olmuştur. Aynı reçete ile haşıllama yapılmasına karşın rotor ipliklerinin iyi emici özellikleri nedeniyle daha fazla miktarda haşıl alımı olduğu ve bu nedenle rotor iplik mukavemet değerinde daha fazla artış görüldüğü düşünülmektedir. Literatürde rotor ipliklerinin ring ipliklerine göre daha emici oldukları ile ilgili bilgiler de mevcuttur $[2,3,11,12]$.

Çizelge 2. İplik test sonuçları

\begin{tabular}{|l|c|c|c|c|c|c|}
\hline \multirow{2}{*}{ Kalite Parametresi } & \multicolumn{3}{|c|}{ Ring iplik } & \multicolumn{3}{c|}{ Rotor iplik } \\
\cline { 2 - 7 } & Haşılsız & Haşıllı & \% değişim & Haşılsız & Haşıllı & \% değişim \\
\hline Kopma mukavemeti (Rkm) & 19,49 & 22,56 & $\mathbf{+ 1 5 , 7 5}$ & 15,60 & 18,40 & $\mathbf{+ 1 7 , 9 5}$ \\
\hline Kopma uzaması (\%) & 7,77 & 7,81 & $\mathbf{+ 0 , 5}$ & 5,56 & 6,11 & $\mathbf{+ 9 , 8 9}$ \\
\hline Aşınma dayanımı (tur) & 201 & 157 & $\mathbf{- 2 1 , 8 9}$ & 195 & 155 & $\mathbf{- 2 0 , 5 1}$ \\
\hline Düzgünsüzlük (\%U) & 8,64 & 8,44 & $\mathbf{- 2 , 3 1}$ & 10,55 & 9,52 & $\mathbf{- 9 , 7 6}$ \\
\hline İnce yer (-50\%) & 0,0 & 0,0 & $\mathbf{0 , 0}$ & 0,0 & 0,0 & $\mathbf{0 , 0}$ \\
\hline Kalın yer (+50\%) & 12,5 & 15,5 & $\mathbf{+ 2 4 , 0}$ & 77,5 & 21,0 & $\mathbf{- 7 2 , 9 0}$ \\
\hline Neps* & 14,0 & 26,0 & $\mathbf{+ 8 5 , 7 1}$ & 12,5 & 1,5 & $\mathbf{- 8 8 , 0}$ \\
\hline Tüylülük (H) & 10,04 & 3,39 & $\mathbf{- 6 6 , 2 4}$ & 7,76 & 3,54 & $\mathbf{- 5 4 , 3 8}$ \\
\hline
\end{tabular}

* Ring için $+200 \%$, Rotor için $+280 \%$ (OE-rotor eğirme prosesindeki sarılmış lifler nedeni ile) 
Ring eğirmede ipliğe dişarıdan büküm verilmektedir ve bükümün helis açısı ipliğin dışından içeriye doğru azalmaktadır. Bu durum iplik içerisinde rezerve elyafların bulunmasına sebep olmaktadır. Rezerve elyafların ise kopma uzamasını arttırdığı düşünülmektedir. Open-End rotor ipliklerde büküm içeriden dişarıya doğru olduğundan, kopma uzamasına maruz kalacak olan elyaflar da merkezdeki elyaflar olarak değerlendirildiğinden, kopma esnasında kopmaya karşı mukavemet gösterecek olan elyaflar merkezdeki elyaflardır. Bu yüzden, eksene paralel olan merkezdeki elyaflar kopma uzaması değerini düşürdüğünden open-end rotor iplikçilikte kopma uzaması değerleri düşüktür [13]. Genellikle haşıllama işlemi sırasında ipliklerin uzama değerlerinde azalma beklenir. Ring iplikleri için, haşıllama işlemleri sırasında orijinal uzamada azalma gözlemlenir. Bununla birlikte, open-end ipliklerde uzamadaki değişim ihmal edilebilir ve hatta uzamada bir artış görünebilir. Dokumadaki performansı açısından iplik uzamasının \%4,5'in altına düşmesine izin verilmemesi tavsiye edilir [14]. Test sonuçlarına göre (Çizelge 2 ve Şekil 8), ring ipliklerinde haşıllama işlemi ile kopma uzamasında \%0,5 oranında artış olurken rotor ipliklerinde bu artı̧̧ \%9,89 oranında gerçekleşmiştir.

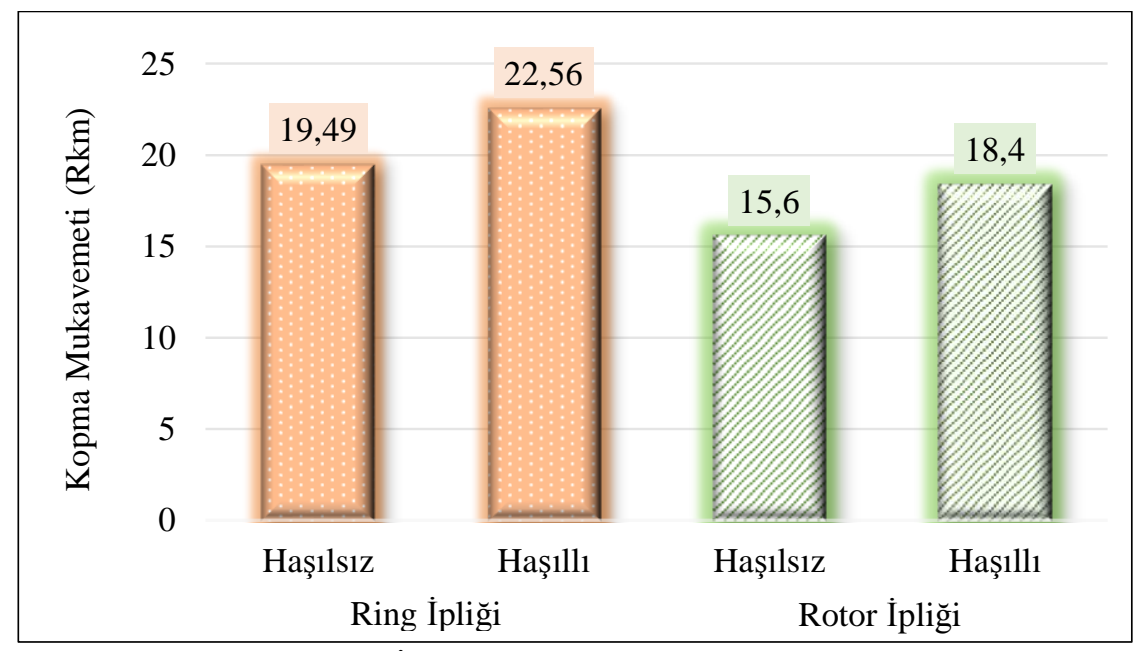

Şekil 7. İplik kopma mukavemeti değişimi

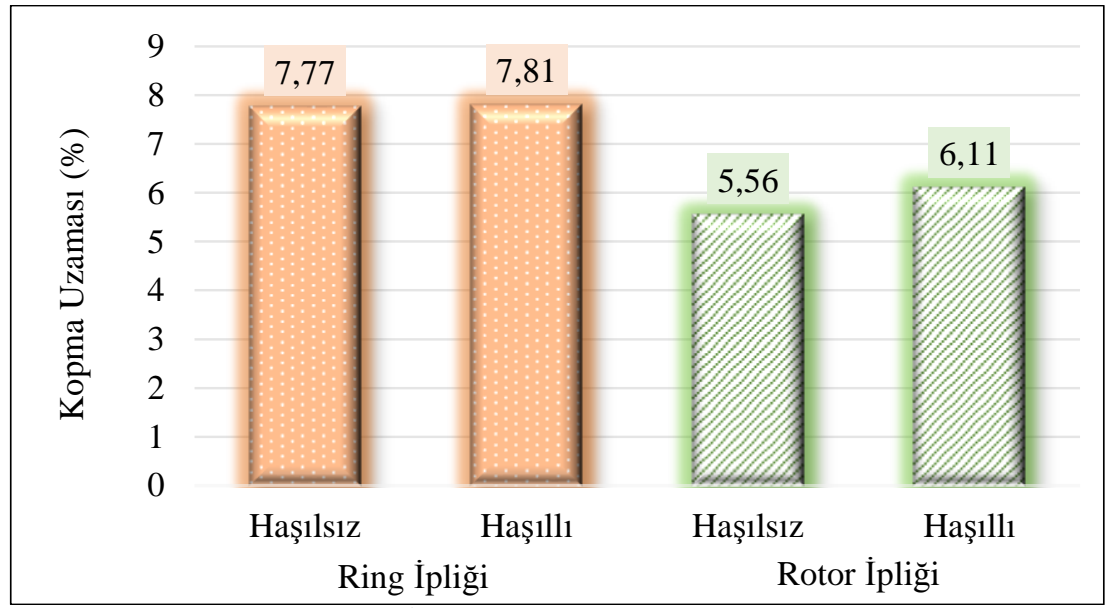

Şekil 8. İplik kopma uzaması değişimi 


\section{2. İplik Aşınma Dayanımı}

Rotor ipliklerinin yapısındaki sargı lifleri nispeten az yük taşır ve bu nedenle, aş̧ındığında ipliğin mukavemeti ciddi şekilde etkilenmez. Bu nedenle genel olarak rotor ipliklerinin yüksek aşınma dayanımına sahip olduğu bilinir $[3,4,15]$. Ancak bu çalışmada haşılsız ring ipliklerinin aşınma dayanımı bir miktar daha yüksek çıkmıştır. Haşıllama işlemi ile hem ring hem de rotor ipliklerinin aşınma dayanımında ilginç bir şekilde azalma görülmüsşür. Oysaki haşıl ile iplik aşınma dayanımının artması beklenir [16]. Konvansiyonel haşıllamada kontakt kurutma yapılmakta ve haşıl filminin iplik yüzeyine düzgün bir şekilde taşınması sağlanmaktadır. Bobinden bobine haşı1 makinesinde sicak hava üflemeli kurutmanın yeterince etkin olmadığı, haşıl filminin yüzeye düzgün taşınamadığı ve bu nedenle haş1 sonrası aşınma dayanımının azaldığı düşünülmektedir. Benzer bir sonuca nişasta haşılı ile yapılan çalışmada da rastlanmıştır [7]. Haşıllama sonrası ring ipliklerinin aşınma dayanımı değeri \%21,89 azalırken, rotor ipliklerinde bu azalma \%20,51 düzeyinde olmuştur.

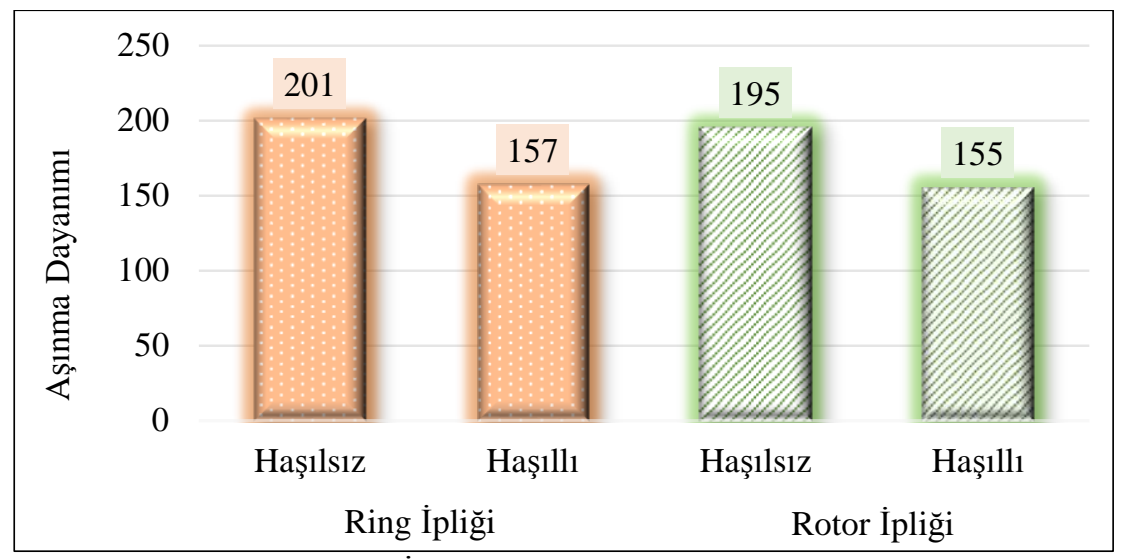

Şekil 9. İplik aşınma dayanımı değişimi

\section{3. İplik Düzgünsüzlüğü ve Hatalar}

Ring iplikleri ile rotor ipliklerinin düzgünsüzlük değerleri genel olarak birbirine yakın ve iyi olarak değerlendirilmektedir [17]. Haşıllama sonrası ring ipliklerinin düzgünsüzlük değeri \%2,31 azalırken, rotor ipliklerinde bu azalma \%9,76 düzeyinde olmuştur.

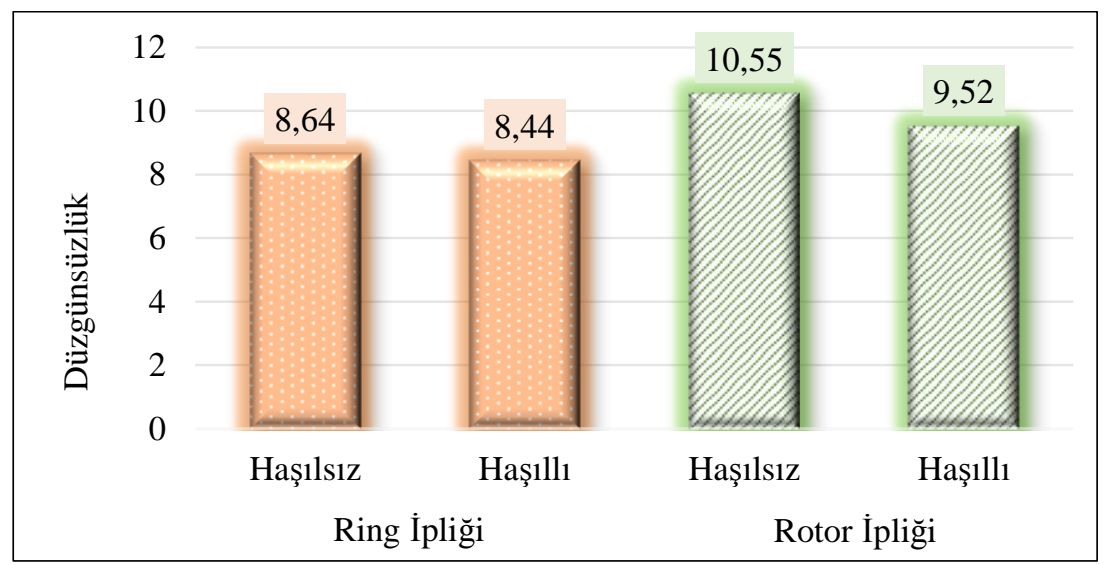

Şekil 10. İplik düzgünsüzlük değişimi 
Ring ve rotor ipliklerinde gerek haşıl öncesi ve gerekse de haşıl sonrası ince yer hatası görülmemiştir (Çizelge 2).

Genel olarak kalın yer hatası rotor ipliklerde daha fazla, neps ise daha düşüktür [12]. Ring ipliklerde haşıllama işlemi ile kalın yer hatası artarken
(\%24), rotor ipliklerde haşıllama işlemi ile kalın yer hatası önemli oranda $(\% 72,90)$ azalmıştır (Şekil 11).

Haşıllama işlemi ile ring ipliklerde neps artarken rotor ipliklerde önemli oranda (\%88) azalmıştır (Şekil 12).

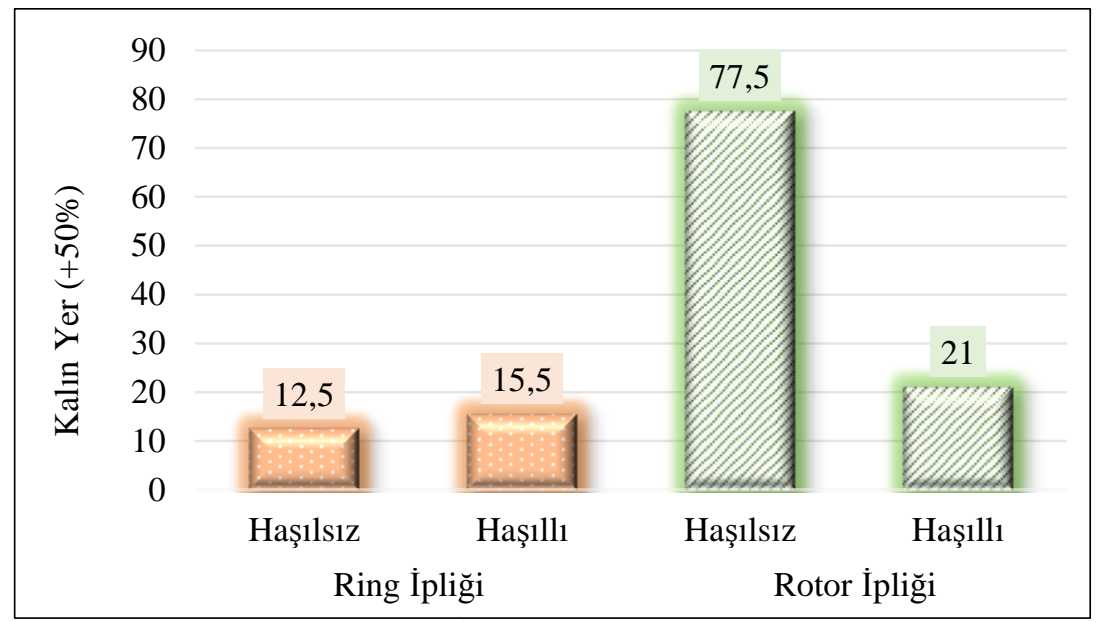

Şekil 11. İplik kalın yer değişimi

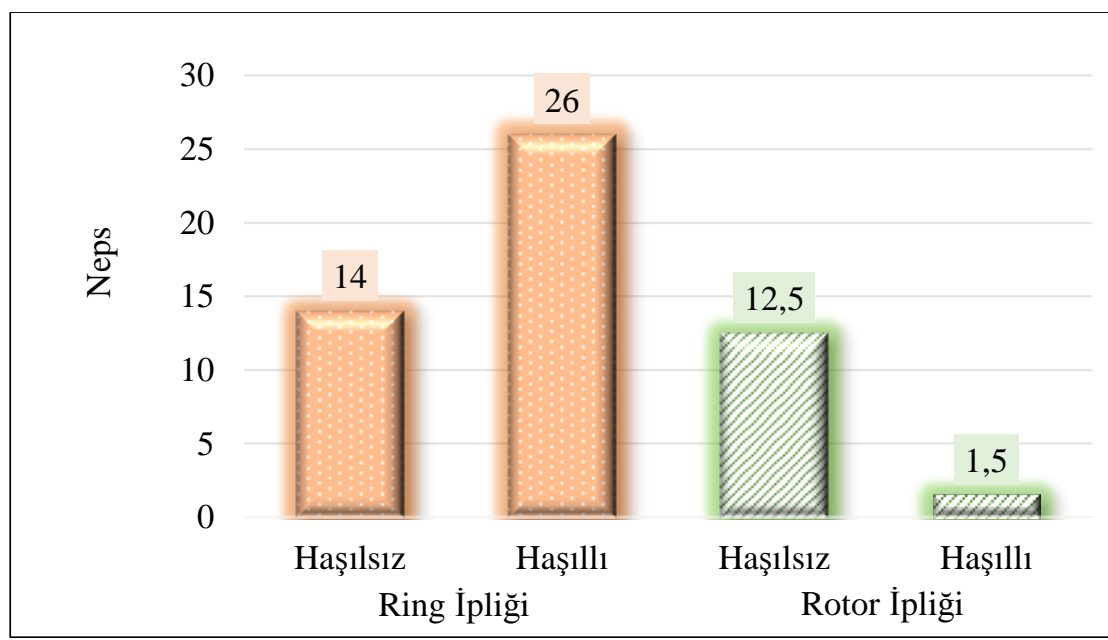

Şekil 12. İplik neps değişimi

\section{4. İplik Tüylülüğ̈̈}

İplik tüylülüğünün rotor ipliklerinde daha az olduğu bilinmektedir [15, 17]. OE-rotor eğirme sisteminde iplik eksenine dik yönde oluşan kuşaklar (sargı lifleri) tüylülüğü engelleyen bir durum olarak öne çıkmaktadır. Ring eğirmede bükümün dışarıdan verilmesi, eğirme üçgeni ve verilen büküm esnasında oluşan sürtünmeler tüylülüğü arttırmaktadır. Rotor iplik tüylülük değeri, ring ipliğine göre \%20-40 daha düşük olarak belirtilmiştir [13]. Çizelge 2 ve Şekil 13'te 
görüleceği üzere haşıllama öncesi rotor ipliklerinin tüylülüğü ring ipliklere göre daha azdır. Haşıllama işlemi sonrasında tüyler iplik yapısına (gövdesine) yapışacağından tüylülük azalmaktadır. Şekil 13'te görüleceği üzere hem ring hem de rotor ipliklerinde haşıllama ile tüylülük azalmıştır. Haşıllama sonrası ring ipliklerinin tüylülüğü $\% 66,24$ azalırken, rotor ipliklerinde bu azalma $\% 54,38$ düzeyinde olmuştur.

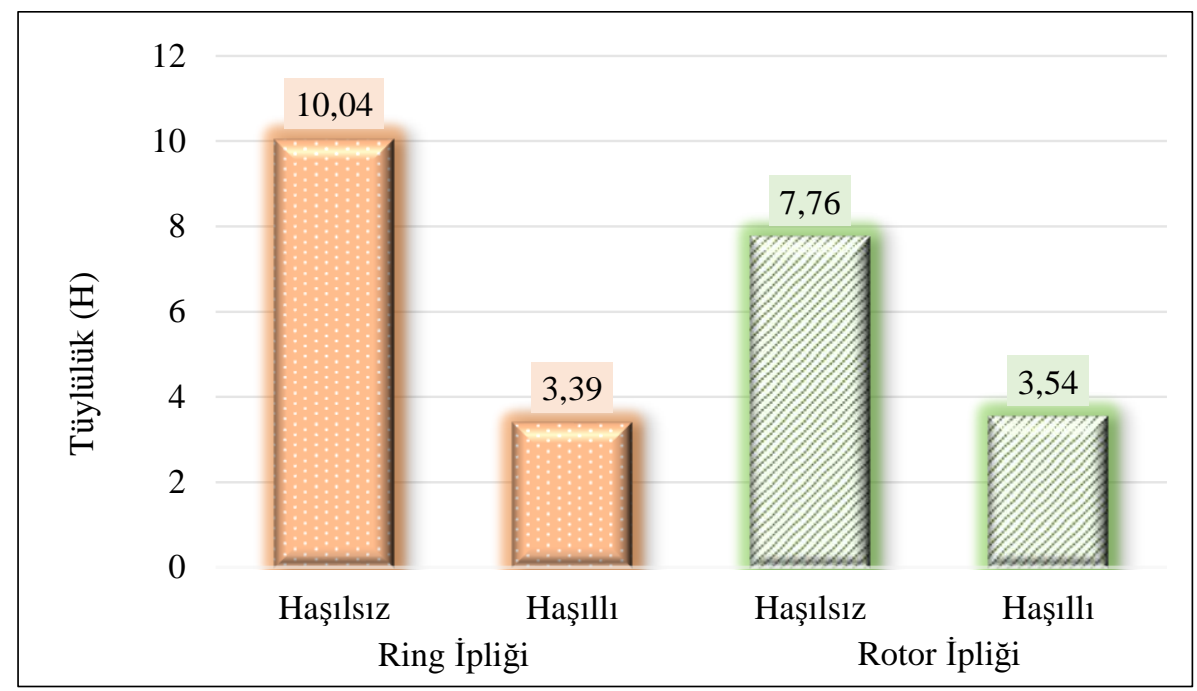

Şekil 13. İplik tüylülük değişimi

\section{SONUÇLAR}

Çalışmada, farklı iplik yapılarının haşıl alımını ve sonrasında iplik kalite parametrelerini nasıl etkileyeceği araştırılmıştır. Sonuçlar aşağıda özetlenmiştir.

- Haşıllama işlemi ile her iki eğirme sisteminde de mukavemet artmıştır. Ancak haşıllama işlemi ile mukavemetteki artış rotor ipliklerinde daha fazla olmuştur.

- Ring eğirme sisteminde haşıllama ile kopma uzamasında çok az miktarda değişim gözlenirken rotor eğirme sisteminde iplik yapısından dolayı kopma uzamasında çok daha fazla değişim gözlenmiştir.

- Haşıllama işlemi sonrası her iki eğirme sistemi için iplik aşınma dayanımında azalma görülmüştür ve bu durum bobinden bobine haşıl makinesindeki efektif olmayan kurutma sistemi ile açıklanmıştır. Haşıl sonrası ring ve rotor iplik aşınma dayanımları birbirine yakın çıkmıştır.
- Haşıllama sonrası düzgünsüzlük, kalın yer ve neps sayılarındaki azalma rotor ipliklerinde çok daha fazla olmuştur.

- Haşıllama öncesi çok daha yüksek olan ring iplik tüylülüğü, haşıl sonrası rotor iplik tüylülüğü ile yaklaşık olarak aynı seviyeye gelmiştir.

Çalışma sonuçları göstermiştir ki rotor iplik yapısı daha hacimli ve daha emici olduğu için rotor ipliklerinde haşıl alımı ring ipliklere göre daha fazla olacaktır. Bu nedenle aynı hammadde ile üretilen aynı numaradaki ring ve rotor ipliklerini aynı haşıl alma oranı ile haşıllamak yerine rotor ipliklerine daha az haşıl verilerek dokumada yeterli performans sağlanacağı düşünülmektedir. Böylece haşıllama maliyetinde tasarrufu sağlanabilecektir.

Daha farklı iplik yapıları ile daha geniş numara aralığında ve işletme şartlarında bir çalışma planlanmaktadır. 


\section{KAYNAKLAR}

1. Goswami, B.C., Anandjiwala, R.D., Hall, D., M., 2004. Textile Sizing. Marcel Dekker, Inc., U.S.A, 400.

2. Schwarz, I.G., Kovacevic, S., Dimitrovski, K., 2010. Analysis of Changes in Mechanical and Deformation Properties of Yarn by Sizing. Textile Research Journal, 81(5), 545-555.

3. Biermann, I., Weidner-Bohnenberger, S., Rieter Com $4{ }^{\circledR}$ Rotor İpliği. Rieter, 2584-v1 tr 1307.

4. Lord, P.R., 2003. Handbook of Yarn Production. Technology, Science and Economics, Woodhead Publishing Ltd., 504.

5. Soe, A.K., Takahashi, M., Nakajima, M., Matsuo, T., 2004. Structure and Properties of MVS Yarns in Comparison with Ring Yarns and Open-End Rotor Spun Yarns, Textile Research Journal, 74(9), 815-826.

6. Thomas, H.L., Zeiba, J.M., 2000. Size Lubrication Methods for Air-Jet-Spun and Ring-Spun Warp Yarns. The Journal of Cotton Science, 4(2), 112-123.

7. Sengupta, A.K., Pratihar, P., Kimothi, P.D., Vernekar, S., Alamgir Sayeed, M.M., 2002a. Influence of Yarn Structure, Sizing Ingredients and Type of Sizing on Properties and Performance of Sized Yarns: Part I-Evaluation of Sizing Process Using Zweigle G55 1 Weavability Tester, Indian Journal of Fibre \& Textile Research, 27, 59-64.

8. Sengupta, A.K., Pratihar, P., Kimothi, P.D., Vernekar, S., Alamgir Sayeed, M.M., 2002b. Influence of Yarn Structure, Sizing Ingredients and Type of Sizing on Properties and Performance of Sized Yarns: Part II-A Comparative Study of Sized Yarn Performance for Ring and Rotor-Spun Yarns. Indian Journal of Fibre \& Textile Research, 27, 142-148.

9. Sengupta, A.K., Pratihar, P., Kimothi, P.D., Vernekar, S., Alamgir Sayeed, M.M., 2002c. Influence of Yarn Structure, Sizing Ingredients and Type of Sizing on Properties and Performance of Sized Yarns: Part III - A Study of Attrition During Weaving for Air-Jet, Ring and Rotor Yarns on a Modern High Speed Weaving Machine. Indian Journal of Fibre \& Textile Research, 27, 149-155.
10. Behera, B.K., Joshi, V.K., 2006. Effect of Sizing on Weavability of Dref Yarns. AUTEX Research Journal, 6(3), 142-147.

11.Özdemir, H., Oğulata, R.T., 2017. Comparison of Color Values of Packages Wound From Different Spun Yarns. Tekstil ve Mühendis, 24(107), 152-159.

12. Özdemir, H., Oğulata, R.T., 2010. Farklı Eğirme Sistemlerinin Boyamaya Hazır Yumuşak Bobinlerin Sertlik Değerlerine Etkisi, Çukurova Üniversitesi Müh. Mim. Fak. Dergisi, 25(1-2), 33-44.

13. Küpeli, Ç., 2019. Farklı Eğirme Sistemlerinde Üretilmiş Polyester-Viskon İplik Özelliklerinin İncelenmesi. Erciyes Üniversitesi, Tekstil Mühendisliği Anabilim Dalı, Yüksek Lisans Tezi, Kayseri, 89.

14. Celanese Chemicals, 2002. Celvol ${ }^{\mathrm{TM}}$ Polyvinyl Alcohol for Textile Warp Sizing, Sayfa No: 14.

15.Textile Spinning, Textile Technology Knowledge Series Volume II, TEXCOMS Textile Solutions, April 21, 2019.

16. Kumaş, Z., 2017. Farklı Haşıllama İşlemlerinin Haşı Alma ve Dokuma Verimliliğine Etkilerinin Araştırılması. Yüksek Lisans Tezi, Çukurova Üniversitesi, Fen Bilimleri Enstitüsü, Yüksek Lisans Tezi, Adana, 256.

17. Kılıç, M., Balcı Kılıç, G., Okur, A., 2011. Eğirme Sisteminin İplik Özelliklerine Etkileri, Tekstil ve Mühendis Dergisi, 18(81), 22-34. 
